\title{
A novel biocoagulant agent from mushroom chitosan as water and wastewater therapy
}

\begin{abstract}
A new commercial cationic polyelectrolyte chitosan (CM), obtained from the waste of mushroom production, was examined using models of water and wastewater namely kaolin and palm oil mill effluent (pome). As it is biocompatible, widely available, and economically feasible, chitosan mushroom has high potential to be a suitable replacement for alum. Also, it can be a promising alternative to chitosan obtained traditionally from Crustaceans due to its higher zeta potential and homogeneity based on the raw material required for its production. A wide range of coagulant dose (5-60 mg 1-1) and wastewater $\mathrm{pH}(2-12)$ were taken into account to find the optimal conditions of coagulation. The optimal doses are 10 and $20 \mathrm{mg} \mathrm{1-1}$ at best $\mathrm{pH}$ (11 and 3) when treated with kaolin and palm oil mill effluent, respectively, while $1200 \mathrm{mg} \mathrm{1-1}$ of alum was not enough to reach the efficiency of chitosan mushroom. On the other hand, the optimum dose of chitosan mushroom (20 mg 1-1) at $\mathrm{pH} 3$ of pome produced $(75,73$, and $98 \%)$ removal of chemical oxygen demand (COD), biological oxygen demand (BOD), and total suspended solids (TSS), respectively. The significant potential of chitosan mushroom was proved by zeta potential measurement. Indeed, it possesses the highest zeta potential $(+70 \mathrm{mV})$ as compared to the traditional chitosan produced from crustaceans. In short, chitosan mushroom as a biocoagulant is eco-friendly and it enhances water quality that meets the requirements of environmental conservatives.
\end{abstract}

Keyword: Biocoagulant; Chitosan; Coagulation; Wastewater; Water 